\title{
THE EQUILIBRIUM OWNERSHIP OF AN INTERNATIONAL OLIGOPOLY*
}

\author{
Henrik Horn \\ World Trade Organization \\ Institute for International Economic Studies, Stockholm University \\ CEPR \\ Lars Persson \\ The Research Institute of Industrial Economics, Stockholm
}

June 10, 1999

\begin{abstract}
Mergers and acquisitions (M\&A) is the dominant form of Foreign Direct Investment (FDI), but has received but scarce attention in the theory literature on trade and investment. This paper highlights how the international pattern of ownership of productive assets may depend on features of trade and production costs. It suggests how high trade costs may be conducive to national ownership of assets, while international firms may arise at lower trade costs, contrary to what the "tariff jumping" argument would suggest. It also shows how private and social incentives for M\&A may differ for weak merger synergies, but converge when synergies are stronger.
\end{abstract}

JEL CLASSIFICATION NO: F23, L13

KEYWORDS: International mergers, endogenous market structure, tariff jumping FDI.

\footnotetext{
${ }^{*}$ Horn is currently on leave from the Institute for International Economic Studies, Stockholm University. Opinions expressed in this paper are not intended to reflect those of the WTO. We are grateful for helpful discussions with, in particular, Wilfred Ethier, Joseph Francois, Dan Kovenock and Harald Lang, and Johan Stennek. We have also benefitted from useful comments by, and discussions with Pedro Barros, John Fingleton and Tony Venables, and by participants in seminars at the Institute for International Economic Studies, the University of Leuven, the University of Lund, the NBER Summer Institute in International Trade, the Stockholm School of Economics and the IUI Workshop on Multinational Production. Financial support by the Bank of Sweden Tercentenary Foundation, and Tom Hedelius' and Jan Wallander's Research Foundations, is gratefully acknowledged. Email: henrik.horn@wto.org and larsp@iui.se.
} 


\section{Introduction}

Mergers and acquisitions (M\&A) is today the dominant form of Foreign Direct Investment (FDI) in the advanced countries in general, and in Europe and the US. in particular. More than half of foreign company investment take the form of M\&A. ${ }^{1}$ In 1994, for instance, more than $90 \%$ of US. inward FDI came through M\&A, and the average for the period 1989-94 was over 80\%. Moreover, crossborder M\&A in western industrialized countries involving majority holdings were valued at $\$ 236 \mathrm{bn}$ in 1997 , or nearly $60 \%$ of total FDI. ${ }^{2}$ It has also become a major mode of industry restructuring in response to trade liberalization. For instance, an evaluation of the European Single Market Program found that M\&A constitute the main source of restructuring, being significantly more important than e.g. internal growth and decline of firms, or exit and entry. ${ }^{3}$

International M\&A are not only quantitatively important, but are in policy making often viewed differently than those involving national firms only. For instance, many countries restrict the right of foreign individuals and firms to acquire domestic firms, or apply special restrictions to foreign firms in certain industries. Governments sometimes allow or encourage mergers between domestic firms that have adverse effects on domestic consumers, with the aim of promoting internationally competitive "national champions". 4 There is also an ongoing debate on the need for international agreements on competition policies. It is feared that countries may undermine international agreements on trade liberalization by increasingly promoting national interests through, e.g., merger policies that discriminate between domestic and international mergers. ${ }^{5}$ Yet another example is the discussion concerning some recent large mergers or acquisitions with international dimensions, such as those involving Boeing and McDonnell-Douglas, Chrysler and Daimler-Benz, Amoco and British Petroleum, and the alliance be-

\footnotetext{
${ }^{1}$ See JETRO (1996), and UNCTAD (1996).

${ }^{2}$ UNCTAD (1998).

${ }^{3}$ See EU (1996).

${ }^{4}$ Such considerations have been important in e.g. Sweden and Canada, but also in larger countries such as France. See e.g. Scherer (1994), and the references therein to Jenny (1990).

${ }^{5}$ See, e.g., Economic Report of the President (1995), or OECD (1988, 1995).
} 
tween American Airlines and British Airways.

Despite the importance of M\&A, they have received but scarce attention in the theory literature on foreign direct investment (FDI) and multinational enterprises (MNE); this literature is surveyed in Markusen (1995). In terms of Dunning's (1977) "Ownership-Location-Internalization" (OLI) framework, most of this literature focuses on the location decisions of firms, taking ownership and the need to internalize as given. In papers such as Markusen (1984), Horstmann and Markusen (1987, 1992) and Markusen and Venables (1996), the focus is the trade-off between the costs of running international operations in terms of duplication of plant-specific fixed costs, and the gains from local production in terms of e.g. lower trade costs. A central question in this literature is how production technologies, factor endowments, trade costs, etc., affect firms' propensity to become international. Most of this literature does not explicitly address the question of whether entry into the foreign market is greenfield, or through M\&A.

There is also a small and mostly recent theoretical literature that more directly address aspects of mergers in international markets. ${ }^{6}$ Building on the Industrial Organization (IO) literature on mergers, this line of research considers mergers between exogenously chosen groups of firms, and focuses mainly on the implications for merger regulation. If merger incentives are taken into consideration at all, a group of firms is typically said to have incentives to merge if the profits of the merged entity in the new equilibrium is higher than the combined profits of the merging firms before the merger; this is the traditional criterion for merger incentives in the IO literature. It is thus implicitly assumed that by rejecting a merger, the firms are guaranteed the profits of the initial situation, and that if they merge, no other merger will take place. Typically, no explanation is offered why other mergers cannot take place.

We will in this paper highlight the role of M\&A as determinants of the patterns of ownership in international oligopolies. Our object of study is a concentrated international oligopolistic market in which entry is restricted because of

\footnotetext{
${ }^{6}$ It includes papers by Ordover and Willig (1986), Barros and Cabral (1994), Head and Reis (1995), Richardson (1996), Rysman (1997), and Horn and Levinsohn (1997).
} 
firm-specific ownership advantages of incumbents. These advantages may stem from, for instance, superior technologies, privileged access to distribution channels, or ownership of extraction rights for natural resources, emission rights for environmental pollution, landing slots at airports, scarce land, etc.. The limited availability of these assets gives rise to an oligopolistic market structure, and provides incentives for firms to merge.

In order to capture a market of this type, we consider a minimal symmetric model of an oligopolistic industry, which sells its output in two segmented markets. In order to produce in this industry, a firms needs at least one unit of an indivisible asset, which are in fixed supply. The interaction takes place in two stages. The structure of the industry is determined in a first stage, in which asset owners can merge domestically or with foreign asset owner(s) in order to form firms. In the second stage the resulting firms compete in Cournot fashion. The international feature of the model is that when national firms export, they face a trade cost in addition to their normal production costs. This cost can be avoid, however, through a merger with a foreign firm. Our basic task is to determine the pattern of mergers in this oligopolistic industry.

To determine the pattern of mergers, we employ an approach developed in Horn and Persson (1997). Its starting point is the observation that since firms are free to communicate about mergers, and can sign binding contracts, it is natural to treat merger formation as a cooperative game of coalition formation (especially, considering the lack of a suitable non-cooperative representation). Standard cooperative models have a basic short-coming, however, and have to be modified to capture mergers in an interesting way. Without going into details, standard cooperative models do not capture externalities between coalitions. ${ }^{7}$ However, in concentrated oligopolistic markets one would expect the consequences of outside mergers to be important, and the underlying coalition model, which is modified to take these externalities into account. Our approach has several advantages. First, it captures the kind of externality that is the defining feature of imperfectly competitive markets. Secondly, it generalizes the criterion for

\footnotetext{
${ }^{7}$ For a discussion of this, see e.g. Shubik (1983, p. 354), or Greenberg (1994, p. 1308).
} 
merger incentives that is employed in the IO merger literature, in a sense to be made clear below. Thirdly, even though it does not yield precise predictions for the division of payoffs in mergers, it seems consistent with the inherent feature of merger formation, i.e. that payoffs (the terms of the merger) are agreed upon at the time when the merger is formed. Incorporating this simultaneity is a central difficulty in modeling merger formation. ${ }^{8}$

The paper proceeds as follows. Section 2 lays out the simple model of an international oligopoly, and then presents the model of endogenous determination of mergers. This model is employed in the ensuing Section 3 to determine the equilibrium pattern of ownership, that is, the equilibrium market structure. In Section 4 we consider some welfare aspects of mergers in international markets. The concluding discussion in Section 5 makes some observations concerning merger and trade policy when mergers are viewed as endogenous. It also discusses several of the weaknesses of the analysis. Finally, most of the proofs are in the Appendix.

\section{The model}

For expositional simplicity, we will work with the minimal symmetric model in which either national or international firms may arise. Thus, let there be two symmetric countries, A and B, and four owners, each endowed with an identical unit of an asset necessary for producing a homogenous product. ${ }^{9}$ Owners 1 and 2 and their assets are located in market $\mathrm{A}$, and owners 3 and 4 reside in market $\mathrm{B}$ with their assets. The interaction takes place in two stages. In the first stage, the owners decide on the formation of the firms, and in the second stage, these firms compete in an oligopolistic international market. In Section 2.1 we describe the international oligopoly market, and in the ensuing Section we lay out the model

\footnotetext{
8 There are well-developed non-cooperative models that capture the alternative scenario, where coalitions are formed first, and only then do the players determine the division of the payoffs. Unfortunately, these models do not seem descriptive of merger formation.

${ }^{9}$ The results in the paper do not qualitatively hinge on the assumption that there are four units of the asset; see Horn and Persson (1997) for more details on the underlying model of merger formation..
} 
of endogenous merger formation.

\subsection{The international oligopoly}

In the second stage, there is in each country an identical linear demand $p=1-Q$ for the industry's product. The markets are segmented on the demand side. Firms compete non-cooperatively in Cournot fashion in the two markets, and the marginal costs of production are output independent (in order to keep the markets strategically separated).

Firms are either national, employing asset(s) from one country only, or international, utilizing assets from both countries. National firms have a cost disadvantage $t$ per unit of output when serving their foreign markets. We assume throughout that $0 \leq t \leq 1 / 2$ to ensure that outputs are positive. In order to capture the notion that exporters may reduce their trade costs by merging with local producers, we will assume that when owners based in different markets merge their assets, the merged entity avoids the trade costs in both markets. ${ }^{10}$ This assumption is extreme in two respects. One is that the trade costs disappear completely through the merger. This simplifies the notation and the analysis, but is of no fundamental importance. The other is that it does not matter whether is one or two foreign assets merge with a domestic asset, in both cases the trade costs disappear entirely. This assumption is less innocuous but it is analytically convenient, since it reduces the number of market structures to be considered significantly.

The symmetry of the model implies that there are 15 possible ownership structures that can be divided into 9 categories or "market structures", where, within each category, firms with the same amount of productive assets make the

\footnotetext{
${ }^{10}$ We deliberately avoid making any specific interpretation of $t$. However, there are several possible interpretations. The most immediate would be to let it refer to physical trade costs. Such costs can be avoided in an international firm since it can sell to a market using its local production facility (asset). This interpretation requires that these facilities are not moved internationally by the merger. This is consistent with a situation where the merger gives rise to savings of fixed overhead cost. If the merger lowers variable costs, the interpretation may be that the merged firm can combine knowledge, permitting it to produce at a lower cost in both units.
} 
same profits:

1. The fully decentralized structure: $M^{O}=\{1,2,3,4\}$.

2. The triopoly where there is only a domestic merger: $M^{T}=\{12,3,4\}$.

3. The triopoly where there is only a foreign merger: $M^{U}=\{1,2,34\}$.

4. Triopolies with international mergers: $M^{V}=\{13,2,4\}, M^{X}=\{1,24,3\}$, $M^{Y}=\{1,23,4\}$, and $M^{Z}=\{14,2,3\}$.

5. The duopoly where there are two national mergers: $M^{N}=\{12,34\}$.

6. The duopoly structures where there are two international mergers: $M^{I}=$ $\{13,24\}$ and $M^{I^{\prime}}=\{14,23\}$.

7. The asymmetric duopoly structures where three assets are merged with a domestic bias: $M^{H}=\{123,4\}$ and $M^{H^{\prime}}=\{124,3\}$.

8. The asymmetric duopoly structures where three assets are merged with a foreign bias: $M^{F}=\{134,2\}$ and $M^{F^{\prime}}=\{1,234\}$.

9. The completely monopolized structure: $M^{M}=\{1234\}$.

In order to save on notation, we henceforth as far as possible refer to each of these categories by referring to their respective first structure.

There are thus two kinds of asymmetries between firms. The first is between national and international firms - the former but not the latter faces the trade cost $t$. The second is between firms with different amounts of assets, and we will here consider three different ways in which the amount of assets of a firm affect its costs. However, the model is completely symmetric in the sense that owners have symmetric access to technology and to partners. The purpose of this symmetry is to highlight how the incentives to form either domestic or international mergers are influenced by the trade cost.

The model has the property that whenever a monopoly makes a larger profit than the combined profits of all firms in more decentralized market structures, 
a monopoly will be formed, if permitted. We see this as a desirable feature, considering that when forming mergers, owners are free to communicate, and to write binding contracts specifying whatever distribution of profits they desire. However, we are not interested in cases where a monopoly is formed, since we are concerned with the distinction, if any, between domestic and international mergers. There are two basic ways in which a monopoly can be ruled out. One is to assume that the monopoly makes a smaller profit than the combined profits of less concentrated structures. This might be due to e.g. organizational inefficiencies that increase with the absolute size of the firm or with the lack of competition, as emphasized by Porter (1985). In these cases, the absence of the monopoly outcome would be endogenous to the model, but would have to be verified in each particular case. We therefore for simplicity assume that a monopoly would not be permitted by competition authorities.

Let $\mathcal{M}$ denote the set of permitted ownership structures, which encompasses all above-mentioned structures except a monopoly, and let profits of firm $k$ in market structure $M^{j}$ be denoted $\pi_{k}^{j}$, etc..

\subsection{The formation of firms}

We now turn to the first stage of the interaction. The merger formation is treated as a cooperative game of coalition formation. ${ }^{11}$ A central concept is the "dominance relation" dom. The idea is that if a market structure $M^{i}$ is dominated by another structure $M^{j}$, the former will not be the outcome of the merger game, since it is in the interest of the firms that have the power - who in our terminology are "decisive" with respect to $M^{j}$ and $M^{i}$ — to enforce $M^{j}$ whenever $M^{i}$ threatens to be the alternative. The merger model has three basic components: (i) a specification of the owners who determine whether one structure dominates another structure; (ii) a criterion for determining when these owners prefer the

\footnotetext{
11 The model partly relies on an approach (partition function form games) that was developed by Thrall and Lucas (1963), and recently employed in the context of mergers by Espinoza and Inarra (1996). It is expressed as an "abstract system", a concept originating from von Neumann and Morgenstern (1947). For a more extensive discussion, see Greenberg (1994).
} 
former structure to the latter; and (iii) a stability (solution) criterion that selects the ownership structures that are seen as solutions to the merger formation game on basis of all the pairwise dominance rankings.

When forming a merger in the first stage, participating owners can freely choose how to distribute the profit the firm will make among themselves. The only constraint imposed on these payoffs is that each firm distributes exactly the profit it makes in the product market competition stage to its owner(s).

\section{Decisive owners}

We want to define our dominance relation so that for some market structure $M^{j}$ to dominate or block another structure $M^{i}$, all owners involved in forming and breaking up mergers between the two structures, in some sense prefer the dominating structure to the other structure. Which owners should then be expected to be able to influence whether $M^{j}$ dominates $M^{i}$ ? Owners belonging to identical coalitions in the two structures cannot affect whether $M^{j}$ will be formed instead of $M^{i}$, since payments between coalitions are not allowed. But all remaining owners can influence this choice. Either they participate in a non-singleton coalition in structure $M^{j}$ that did not exist in this form in the other structure, which requires the consent of all members of the coalition to be formed. Or, if they stand alone in structure $M^{j}$, and thus lose partners by moving from $M^{i}$ to $M^{j}$, they can offer to forego surplus in structure $M^{i}$ in order to prevent $M^{j}$ from being formed. For instance, for structure $M^{H}=\{123,4\}$ to dominate structure $M^{N}=\{12,34\}$, it is not only required that owners 1,2 and 3 prefer $M^{H}$ to $M^{N}$. If owner 4 is adversely affected by the formation of $M^{H}$, this owner might want to persuade owner 3 to remain in structure $M^{N}$. As a consequence, owner 3 may demand a large share of the joint profit in structure $M^{H}$ from owners 1 and 2, to be willing to forego what 4 is offering for $M^{N}$ to be formed. Hence, by being linked to owner 3 in structure $M^{N}, 4$ is able to "bargain" with 1 and 2 over 3's participation in a merger. We say that owners who are linked this way in a dominance ranking between two structures $M^{i}$ and $M^{j}$ belong to the same decisive group of owners with respect to market structures $M^{i}$ and $M^{j}$, denoted $\mathcal{D}_{g}^{i j}$. Generally speaking, this set of owners is obtained by forming a union of 
firms in $M^{i}$ and a union of firms in $M^{j}$, such that the two unions thus formed contain the same set of owners, the two unions do not have any firms in common, and there is no subset of the set thus formed that can be constructed in the same way. In general, there may exist more than one such group of owners who are internally linked in the two structures, but where the groups have no owners in common - this is indicated by the subscript $g .^{12}$

The formal definition of a decisive group may appear somewhat opaque. However, the concept itself is straightforward, and in "practice" it is very easy to find the decisive groups. For instance, in a dominance ranking of $M^{T}=\{12,3,4\}$ and $M^{O}=\{1,2,3,4\}$, owners 3 and 4 belong to identical firms in both structures, and are hence not decisive. The only decisive group w.r.t. these two structures is hence $\mathcal{D}_{1}^{T O}=\{1,2\}$. Or, in a dominance ranking of $M^{T}=\{12,3,4\}$ and $M^{U}=\{1,2,34\}$, owners 1 and 2 belong to different firms in the two structures, and so do owners 3 and 4 . Hence, all four owners belong to a decisive group. But, since firms 1, 2 and 12, on the one hand, and 3, 4, and 34, on the other, do not have any owners in common, and thus cannot transfer any resources between them, there are two decisive groups, $\mathcal{D}_{1}^{T U}=\{1,2\}$ and $\mathcal{D}_{2}^{T U}=\{3,4\}$.

\section{Dominance}

Having identified the owners who decide whether one market structure dominates another, we now come to the second central question: when should the set of decisive owners be said to prefer one structure to the other? We will say that $M^{j}$ dominates $M^{i}$ via a decisive group if and only if the combined profit of the decisive group is larger in $M^{j}$ than in $M^{i}$. But, with more than one decisive group, these groups may dominate in opposite directions. We therefore require that for $M^{j}$ to dominate $M^{i}$, written $M^{j}$ dom $M^{i}$, domination holds for each decisive group with respect to $M^{i}$ and $M^{j}$. Note that we cannot simultaneously

\footnotetext{
${ }^{12}$ Formally, let $\mathcal{K}^{j}$ be the set of all firms (coalitions) in $M^{j}$, and let $\mathcal{H}^{i}$ be a subset of the firms (coalitions) in $M^{i}: \mathcal{H}^{i} \subseteq \mathcal{K}^{i}$. Also, let $\mathcal{O}\left(\mathcal{H}^{i}\right)$ be the set of owners participating in the coalitions in $\mathcal{H}^{i}$. Define $\mathcal{H}^{j} \subseteq \mathcal{K}^{j}$ and $\mathcal{O}\left(\mathcal{H}^{j}\right)$ analogously. $\mathcal{D}_{g}^{i j}\left(=\mathcal{D}_{q}^{j i}\right)$, and the associated sets of firms $\mathcal{H}_{d}^{i}$ and $\mathcal{H}_{d}^{j}$, then fulfill the following properties:

1. $\mathcal{D}_{g}^{i j}=\mathcal{O}\left(\mathcal{H}_{d}^{i}\right)=\mathcal{O}\left(\mathcal{H}_{d}^{j}\right) \neq \emptyset$.

2. $\mathcal{H}_{d}^{i} \cap \mathcal{H}_{d}^{j}=\emptyset$.

3. $¥ \mathcal{D} \subset \mathcal{D}_{g}^{i j} \mid \mathcal{D}$ fulfills 1 and 2 .
} 
have both that $M^{j}$ dom $M^{i}$ and $M^{i}$ dom $M^{j}$, i.e., that the dom relation is asymmetric.

\section{Equilibrium ownership structures}

The definition of decisive groups and of the dom relation describes how to rank any pair of ownership structures. It remains to specify how to employ these rankings in order to predict the outcome of the merger formation. To this end, define as Equilibrium Ownership Structures (EOS) those structures that are undominated, i.e., that are in the core. ${ }^{13}$ We will also occasionally refer to "equilibrium market structures", meaning market structures induced by the set of EOS. Due to the symmetry of the underlying oligopoly model, the set of EOS may comprise different ownership structures giving rise to the same market structure. For instance, the two ownership structures $M^{I}=\{13,24\}$ and $M^{I^{\prime}}=\{14,23\}$ are different from the point of view of ownership. But, since they give rise to the same market structure, the merger formation model cannot distinguish between the two. Thus, while the set of EOS may consist of up to 14 ownership structures, the maximum number of possible market structures is smaller.

\subsection{The relationship to traditional merger analysis}

It should be noted that the model of merger formation described above includes the traditional criterion for merger incentives, originating in Stigler $(1964,1971)$ and Salant et al (1983), as a special case. It arises when $M^{j}$ is a strict concentration of $M^{i}$ that results from a single merger. In this case our criterion coincides exactly with the traditional criterion. But, the present analysis is a generalization in two respects. First, the dominance relation employed here is more general than the dominance relation implicitly employed in the traditional criterion in two ways. It can be applied to situations where there is more than one concentrative merger, and it permits dominance rankings between ownership structures where neither is a strict concentration of the other. Secondly, the set of feasible structures to which the dominance criterion is applied contains many

\footnotetext{
${ }^{13}$ Formally, EOS is the set $\mathcal{M} \backslash\left\{M^{\prime} \in \mathcal{M} \mid \exists M \in \mathcal{M}\right.$ such that $M$ dom $\left.M^{\prime}\right\}$.
} 
more than the two structures allowed in the traditional analysis. In both respects the present model generalizes the traditional approach to merger analysis.

\section{Equilibrium ownership structures}

We are now set to derive the equilibrium ownership structures in the international oligopoly laid out above. To this end, we employ three specifications of the 'merger technology", i.e., of the way in which mergers impact firms' costs. Assume first that firms produce at zero costs. There are thus no other savings from mergers than possibly savings of trade costs, so purely domestic mergers do not give rise to any cost savings. This will be referred to as the Trade Cost Savings (TCS) Model.

The following partial characterization of the set of EOS in this model is proved in the Appendix:

Proposition 1. In the TCS Model, the EOS is:

(i) $M^{I}$ if $1 / 15<t<1 / 3$,

(ii) $M^{N}$ if $(\sqrt{34}-5) / 2<t<1 / 2$.

Proposition 1 points to three noteworthy features. A first, but far from trivial, observation is that the set of EOS is non-empty for a significant set of values of the trade cost. ${ }^{14}$ It can also be shown that there are values for which this set is empty; in these cases the intransitivity of the dominance relation implies that all ownership structures are dominated. ${ }^{15}$ But, for the remaining values of the trade cost, the model is in this sense "well-behaved".

\footnotetext{
${ }^{14}$ It can be shown that the set of EOS is non-empty also for $1 / 3 \leq t \leq 2 / 5$, and comprises more than one structure. For instance, for $1 / 3 \leq t \leq 2 / 5, M^{I}$ and $M^{V}$ do not dominate each other since the aggregate profits for the decisive groups are exactly the same. Moreover, it can be shown that both structures are undominated in this interval. However, it is established in the next section that even for a very small fixed cost saving from the merger, the unique form of EOS is $M^{I}$ in this interval. Since this model is only intended to point to certain implications of the trade cost, we refrain from fully characterizing the set of EOS, for the sake of brevity.

${ }^{15}$ It can be shown that $M^{I}$ dom $M^{i}, i \neq V, X, Y, Z$ for $t<\frac{1}{3}$, and that $M^{i} d o m M^{I}$, $i=V, X, Y, Z$ for $t<\frac{1}{15}$. Thus $M^{V}, M^{X}, M^{Y}$ and $M^{Z}$ are the only candidates as EOS. But, it also the case that $M^{O} \operatorname{dom} M^{i}, i=V, X, Y, Z$ for $t<\frac{1}{15}$. Consequently there exist no EOS for $t<\frac{1}{15}$. The same type of reasoning applies for $t \in\left(\frac{2}{5},(\sqrt{34}-5) / 2\right)$,
} 
Secondly, as noted above, a central idea in the literature on FDI is the notion that high trade barriers induce firms to become international. ${ }^{16}$ But, the Proposition suggests the opposite, namely that high trade barriers instead lead to domestic ownership of the assets, contrary to the "tariff-jumping" argument! This result is not due to the limited number of owners depicted in the model; it follows from the analysis in Horn and Persson (1997) that the number of owners is immaterial to the result. Nor does the result hinge on the particular merger technology in the TCS Model, as will be shown below.

Finally, note that in the traditional merger analysis there would not be any merger for $t$ low enough unless monopoly was allowed, i.e. $M^{O}$ would be the equilibrium structure. The reason why this is not the case here is that our dominance relation is more general than the one employed in the traditional criterion, since it can be applied to situations where there is more than one concentrative merger. $M^{I}$ dominates $M^{O}$ for $1 / 15<t<1 / 3$ since there are two separate mergers when moving from $M^{O}$ to $M^{I}$. When owner 1 and 3 merge they lose profits, as in the Salant-Switzer-Reynold framework, due to the expansion of output by outsiders. But, they gain from the merger between owners 2 and 4 . The total effect on profits of these two mergers is positive, and $M^{I}$ thus dominates $M^{O}$.

\subsection{EOS when concentration yields savings of fixed cost}

The standard inducement for mergers in Cournot models is fixed cost savings. To capture this incentive, assume that each firm faces a fixed cost $f>0$, while variable production costs continue to be zero as in the previous model. ${ }^{17} \mathrm{~A}$ firm's total costs thus consist of the fixed cost, and a trade costs $t>0$ per unit exported, as long as the firm does not participate in an international merger. An upper bound is also imposed on the size of the fixed cost, a bound that depends on the

and hence there is no EOS in this region either. It is shown in the next section that if there is a fixed cost saving associated with the merger, this non-existence arises only for a very small range of fixed costs.

${ }^{16}$ In the formal MNE literature, such as e.g. Horstmann and Markusen (1992), it also necesarry with cost synergies in order for international firms to arise.

${ }^{17}$ Since the fixed cost is here assumed to be strictly positive, the TCS Model is not a special case of the FCS Model. 
trade cost, to ensure that profits are positive. This model is denoted the Fixed Cost Savings (FCS) Model. The pattern of EOS for this model is graphically illustrated in Fig. $1 .^{18}$ The picture largely corresponds to that obtained in the case of the TCS Model. For lower values of the trade cost, the EOS is a duopoly with two internationally merged firms, whereas a trade cost above $2 / 5$ results in a duopoly with two national firms, provided that the set of EOS is non-empty in both cases.

(Figure 1 here)

\subsection{EOS when concentration yields variable cost synergies}

Another "archetype" oligopoly model in the merger literature, due to Perry and Porter (1985), assumes that mergers reduce variable costs. To capture this feature, we will employ a simplified version of their model, with no fixed cost savings, but where mergers affect variable costs. The constant cost per unit of output in firm $h$ is $1 / k_{h}$, where $k_{h}$ is the amount of capital in firm $h$. The total fixed supply of capital in the market is $k$, and each owner is endowed with $k / 4$ units of capital due to the assumed symmetry. The constant marginal cost is $4 / k$ in a firm with one asset, is $2 / k$ with two assets, and $4 /(3 k)$ with three assets. Thus a merger between the assets of two owners reduces their marginal cost by more than when the two merge with a third owner. ${ }^{19}$

The equilibrium pattern is depicted in Fig. 2. To facilitate the comparison with the FCS Model, Fig. 2 is cast in the $(t, c)$ plane, where $c \equiv 4 / k$ is the constant marginal cost for a firm with only one owner. Observe that a large $c$ corresponds to large synergies, in the sense that the absolute fall in the level of

\footnotetext{
${ }^{18}$ Underlying derivations are available upon request from the authors.

19 The main difference between this model, and that of Perry and Porter, is that in the latter, the marginal cost is linear in output, whereas here it is constant. The present formulation simplifies the analysis considerably, but retains the essential property that mergers reduce marginal costs.

For computational convenience we restrict the range of $k$ to $k \leq 400$, implying that there is an implicit lower bound of $1 / 100$ for the marginal cost in the single asset firm. There are also restrictions that ensure ing that we a monopoly does not arise in either market. Underlying derivations are available upon request from the authors.
} 
the marginal cost from a merger is larger the higher is $c .^{20}$

(Figure 2 here)

The figure reveals a pattern similar to that in both the TCS and FCS Models. For low levels of the trade cost, the set of EOS gives rise to two international duopolies, to the extent that it is non-empty, whereas large trade costs are conducive to domestic mergers. The picture is more complicated than with fixed cost savings, since the asymmetric duopoly structures $M^{H}$ and $M^{F}$ might now dominate the symmetric duopoly structures. This is particularly "likely" to occur for high levels of $c$, i.e., when the synergies from mergers are considerable.

\subsection{Why do trade costs yield incentives for national ownership of firms?}

All three models above suggest that high trade barriers induce domestic rather than international ownership of firms, in contrast to what the tariff-jumping argument would suggest. It thus seems likely that more general forces are at work than perhaps suggested by the different parametric models. It is not difficult to see why a more concentrated structure may dominate structures that are strictly less concentrated. It is less obvious why there are duopoly structures that are not dominated by any triopoly structure. However, the main question seems to be: why is structure $M^{I}$ dominated by structure $M^{N}$, when the former completely removes trade costs whereas the latter is associated with such costs?

In any dominance ranking of duopoly structures, the decisive group comprises all four owners, and will thus involve a comparison of industry profits in the different structures. In order to examine the sources of aggregate profits in a duopoly, consider a market where one of the two firms may or may not face a trade cost, and where the other does not. This setting encompasses all situations that may occur in either of the markets in any of the duopoly structures, since in no structure will both firms face the trade cost. Let the aggregate profit in this

\footnotetext{
${ }^{20}$ The difference in marginal cost in a one-asset-firm and a two-asset-firm is $c / 2$, and the corresponding value when comparing firms with three and two assets is $c / 6$.
} 
market be expressed as

$$
R(t)=\bar{R}(t)-t q_{e}(t)
$$

where $\bar{R}$ is the aggregate profit net trade costs, $q_{e}$ is quantity exported to this market, and $t q_{e}$ thus represents expenditures on trade costs. We can write the aggregate profit in this market as

$$
R(t)=R(0)-t q_{e}(t)+\int_{0}^{t} \frac{d \bar{R}(\tau)}{d t} d \tau
$$

Equation (3.1) decomposes the aggregate profit into three terms. $R(0)$ is the industry profit absent the trade cost. ${ }^{21}$ The second and third components would vanish at $t=0$, and are hence both due to the trade cost. The second term, the direct trade cost, tends to lower aggregate profits relative to those made at $t=0$. The third term measures the increase in aggregate profit net trade costs relative to a situation with $t=0$, that stems from the fact that the trade barrier induces the exporting firm to hold back its output volume more than it induces the other firm to expand its output. This is thus the anti-competitive effect of the trade barrier. It is shown in the Appendix that when the output is homogenous, marginal costs are output independent, and outputs are strategic substitutes, the aggregate profit net of trade costs increases in the trade cost:

$$
\frac{d \bar{R}(\tau)}{d t}>0 \text { for } t \text { such that } q_{e}(t)>0
$$

This implies that the term capturing the anti-competitive effect in (3.1) is positive, and is larger, the higher is the trade barrier. There are thus two counteracting forces that jointly determine whether the trade barrier increases or reduces aggregate profits relative to a situation with $t=0$ in this market.

Now consider why $M^{N}$ may dominate $M^{I}$. Fixed and marginal costs are the same in each firm in both structures. The fact that there is only one decisive group with respect to these structures, comprising all four owners, implies that $M^{I}$ dominates $M^{N}$ if and only if $\pi^{I}>\pi^{N}$, and conversely if $\pi^{I}<\pi^{N}$. It is clear that $\pi^{I}$ is independent of the trade cost, whereas the trade cost affects aggregate profits in structure $M^{N}: \pi^{N}=\pi^{N}(t)$. Also, aggregate profits are the same for

\footnotetext{
${ }^{21}$ If there are fixed costs, we divide them equally betwen the two markets.
} 
$t=0, \pi^{N}(0)=\pi^{I}$. Any difference between the two profit levels is therefore solely due to the trade cost in the two markets. But, since both structures are completely symmetric, it suffices to consider one of the markets only.

We now need to distinguish between profits in the different market structures, and we therefore index $R$ and $q_{e}$ by a market structure specific superscript. It follows from (3.1) that $R^{N}(0)=R^{I}$, since for $t=0$ the two market structures are identical in terms of profits. Thus,

$$
\pi^{N}(t)-\pi^{I}=2\left[\int_{0}^{t} \frac{d \bar{R}^{N}(\tau)}{d t} d \tau-t q_{e}^{N}(t)\right]
$$

Whether or not $M^{I}$ dominates $M^{N}$ depends on the balance between the "barrier jumping" incentive to form $M^{I}$ in order to avoid the direct trade cost $t q_{e}^{N}$, and the anti-competitive incentive to form $M^{N}$. This balance is characterized in the following Proposition, which is proved in the Appendix:

\section{Proposition 2.}

(i) There is a $t^{\prime}$ such that $M^{I} \operatorname{dom} M^{N}$ for $0<t<t^{\prime}$.

(ii) If there is a finite $t^{\prime \prime}$ such that $q_{e}^{N}(t)=0$ for $t \geq t^{\prime \prime}$, there is a $\bar{t}$ such that $t^{\prime}<\bar{t}<t^{\prime \prime}$, and such that $M^{N} \operatorname{dom} M^{I}$ for $t>\bar{t}$.

Intuitively, when owners in the same market merge, they "buy out" the stronger competitor, i.e. the firm with the lower marginal cost. This tends to increase profits in the firm's home market. On the other hand, by merging domestically, the firm foregoes the lower trade costs that an international merger would have brought, reducing the profits made in the foreign market. When the trade cost becomes sufficiently high, each firm comes close to being a monopolist in its home market, and thus spends very little on trade costs. ${ }^{22}$ Each firm will then make a larger profit than if it had participated in duopoly competition in two markets without facing trade costs.

\footnotetext{
${ }^{22}$ Strictly speaking, we do not allow $t$ to become so large that the firms become monopolies in their home markets. However, since $\pi^{N}$ is strictly larger than $\pi^{I}$ at $t=t^{\prime \prime}$, it will by continuity also be larger at a range of lower levels of $t$.
} 


\subsection{On the interpretation of the model}

We have interpreted the decentralized $M^{O}$ as the "initial" structure, in line with the IO merger literature. This enables us to view the move to the EOS as a merger process. But, formally there is nothing special about this structure: the dominance criterion ranks every structure against every other structure. An alternative interpretation of the model would therefore be to say that it "only" predicts the EOS, and that there is no initial allocation. In order to derive predictions concerning mergers, we could then make a "comparative statics" experiment, whereby an exogenous parameter is changed. For instance, starting in an en equilibrium with national firms $\left(M^{N}\right)$, and lowering the trade cost sufficiently, international firms would be formed, through the selling of certain domestic assets, and the merger with the foreign-owned assets. This alternative interpretation would put the analysis more in line with the dominating methodology in the MNE literature.

Much of the literature in this field fits into the "Ownership-Location-Internalization" (OLI) framework, formulated by Dunning (1977). FDI here arises as a result of a firm's desire to exploit ownership advantages in foreign markets. If the difficulties associated with arm's-length transactions are sufficiently severe, firms can only serve foreign markets through exports or local production. Since running foreign operations is inherently more costly than producing at home, it takes some cost advantage from local production to make it preferable to home production. There are many possible such factors, including e.g. lower factor prices. But, often mentioned are cost disadvantages associated with exports such as regular transport costs, tariffs, and non-tariff barriers, or costs that stem from limited understanding of local tastes, limited access to distribution networks, and so on. A central tenant in the FDI literature has been the notion that these costs provide incentives for firms to avoid trade barriers by investing in local markets. In this paper it is argued that one also has to take into account how the incentives to form other market structures are affected by these barriers. Trade costs do tend to make local production advantageous. But, they also cause location disadvantages in that they tend to drive up the demand for the assets in which the FDI would take place. The latter effect will dominate the former 
in most oligopoly models, for sufficiently high trade costs and concentrated local market structures, with our model of merger formation.

\section{Welfare}

A central question is whether the merger market mechanism selects the market structures that are most preferred from a social point of view. In order to address this question, we first make a couple of more general remarks about welfare evaluations of market structures (and thus of mergers) in international markets.

In a closed economy, the conventional welfare evaluations of mergers and market structures is typically made by comparing the sum of domestic consumer surplus and profits in different market structures. But welfare evaluations of market structures differ fundamentally in a closed and an open economy. First, in the case of an open economy, the national welfare criterion would typically only include a subset of all consumers, those who are nationals of the country in question. Secondly, and more problematically, in the case of an international merger, it is necessary to take the division of surplus in the merger into account. As a result, the practical informational difficulties of making welfare evaluations of mergers, which are often insurmountable already in the case of closed economies, will be significantly harder in the case of international mergers.

Structures that would be identical from a welfare point of view in a closed economy framework, may be viewed very different in an international context. For instance, consider the formation of the two asymmetric duopoly structures $M^{H}$ and $M^{F}$. These mergers are completely symmetric from a closed economy point of view, but may from a welfare point of view be ranked differently, depending on the height of the trade barriers, and on how the surplus is divided in mergers. In order to see this, assume that the share of the profit (net any payments between owners) accruing to the foreign owner in the merged entity, $z$, is the same in the two market structures, an assumption which seems natural considering the symmetry between $M^{H}$ and $M^{F}{ }^{23}$ Let the welfare of country $k$ in structure $M^{i}$

\footnotetext{
${ }^{23}$ This share may in general be a function of $t$, but since we lack a theory for how it is determined, we treat it as a constant.
} 
be denoted $W_{k}^{i}(t), k=A, B$. Taking the symmetry between the structures into account,

$$
W_{A}^{H}(t)-W_{A}^{F}(t)=C S_{A}^{H}(t)-C S_{A}^{F}+(1-2 z) \pi_{123}^{H}(t)-\pi_{4}^{H}(t)
$$

The consumer surpluses are the same in both markets for $t=0$, but will be lower in market $\mathrm{A}$ for positive trade costs (the trade cost does not affect the surplus in market B), and this will provide a tendency for $M^{F}$ to be preferred to $M^{H}$.

Now turn to the profits. In structure $M^{F}$, country A receives the full profit of the outside firm 2 (which by symmetry equals $\pi_{4}^{H}$ ), and a fraction $z$ of the profit of the merged firm 134 (which equals $\pi_{123}^{H}$ ), whereas with structure $M^{H}$ country A gets $(1-z)$ of the merged firm's profit, but no more. Hence, when the merged firm and the outside firm make approximately the same profit, the foreign-biased structure $M^{F}$ is better than the domestically biased structure $M^{H}$. But, when the merged entity makes a sufficiently much larger profit than the outside firm, then the opportunity cost for getting the outside firm's profit — the share of the profit going to foreign agents - becomes too high, and a domestically biased merger becomes preferable. For instance, in the absence of trade costs, it seems natural to assume that $z=1 / 3$, so that the three owners participating in the merger split the profit evenly. Country A will then be better off with structure $M^{H}$ than with structure $M^{F}$ if, and only if,

$$
\pi_{123}^{H}(0)>3 \pi_{4}^{H}(0)
$$

It clearly takes significant synergies for (4.1) to be fulfilled. For instance, in the case of the standard Cournot model with fixed cost savings it cannot be fulfilled, except in the rather special case where the fixed costs in the merged entity 123 are significantly smaller than those in its non-merged competitor. With variable cost synergies it seems more likely that the condition is fulfilled, since the merger does not only have a direct impact on the costs, but also an induced "strategic" effect via lower marginal costs. ${ }^{24}$

\footnotetext{
${ }^{24}$ It might be tempting to interpret condition (4.1) in terms of the "externality" that
} 
As noted above, the merger model does not yield an explicit prediction of the distribution of surplus in the mergers, and thus we cannot make a complete welfare analysis. However, it is shown in Horn and Persson (1997) that if all EOS are permitted except for a monopoly, if the cost synergies associated with the merger are strong enough, and if there are positive externalities from mergers on outsiders, then the set of EOS is non-empty, and consists of those duopoly structures that give rise to the maximal industry profit among all structures. It is possible to show, for instance, that in the FCS Model the EOS will give rise to the market structure that maximizes industry profit. This in turn suggests an inherent possible conflict between the property of the outcome of the merger formation and global welfare, since aggregate profit maximization does not necessarily correspond to welfare maximization.

In order to throw some light on possible conflicts of interests between the countries, we will in the following two Subsections derive the socially most preferred ownership structures in the FCS and the VCS Models. ${ }^{25}$ Lacking a theory of the determination of the division of payoffs, the analysis will be based on the assumption that the EOS has the property that profits are divided evenly in mergers, so that $z=1 / 2$ when two owners are involved, and $z=1 / 3$ when three owners merge their assets. Note, however, that we do not assume that this would be the payoff division in any merger, only that it is the property of the equilibrium merger(s).

\subsection{Most preferred ownership structures in the FCS Model}

One can identify several forces that affect the welfare ranking of the different market structures in the FCS Model. First, as in a closed economy, there is a trade-off between the productive efficiency that concentration entails, and the resulting loss of consumer surplus. But, this trade-off is only part of the picture

plays a central role in traditional merger analysis, i.e., the consequences for the outside party of a concentration in the market. However, this condition does not involve a comparison of situations before and after a merger, but a comparison of the profits of a merged firm with that of its non-merged competitor.

${ }^{25}$ Welfare analysis of the TCS does not add insights beyond those from the FCS and VCS Models, and is thus not presented here. 
in the case of the open economy. In the presence of foreign consumers, part of the cost of a domestic concentration is carried by foreigners. On the other hand, a concentration reduces market shares of those participating in mergers, so domestic concentration will tend to shift profits to foreign firms, and vice versa. Fig. 3 illustrates the pattern of most preferred market structure for country A for different values of $t$ and $f$.

(Figure 3 here)

Several noteworthy features emerge from the figure. First, when the efficiency enhancing consequences of concentration are small - i.e., when both $t$ and $f$ are relatively small - the most preferred structure is not the least concentrated structure $M^{O}$, but a merger between the foreign firms, with the domestic firms remaining as separate entities, i.e., $M^{U}=\{1,2,34\}$. Relative to $M^{O}$, structure $M^{U}$ implies a shift of profits to the domestic firms, both in market A and in B, and this more than compensates for the loss of consumer surplus in A.

Secondly, for a given value of $t$, structure $M^{F}$ is preferred to $M^{U}$ for a sufficiently high fixed cost. The reason is that country A welfare is reduced by fixed costs equal to $2 f$ by the merger to structure $M^{U}$, whereas it is reduced by $(1+z) f$ with $M^{F}$. For a sufficiently high fixed cost $f$ the social cost of maintaining a large national market share becomes too large, and it becomes worthwhile to have a domestic owner participating in the merger between the foreign owners.

A similar reasoning explains why $M^{I}$ increases relative to $M^{F}$ with increasing fixed costs. The points of indifference between $M^{I}$ and $M^{F}$ are illustrated in the figure by the curve $W^{I}=W^{F}$. Above this line $W^{I}>W^{F}$ : country A welfare is reduced by fixed costs equal to $\left(\frac{1}{2}+\frac{1}{2}\right) f$ in structure $M^{I}$, whereas it is reduced by $(1+z) f$ with $M^{F}$. For $f$ large enough the larger fixed cost in $M^{F}$ will dominate the higher variable surplus it may entail.

Thirdly, the curve $W^{I}=W^{F}$ is non-monotonic, since $W^{F}$ first falls and then increases in $t$. As a result, structure $M^{F}$ tends to be preferred for either low trade costs and high fixed costs, or for high trade costs and low fixed costs, but to be inferior to $M^{I}$ when both trade costs and fixed costs are high. Observe 
that $W^{F}$ is affected by $t$ only as it affects the profits made by firms 134 and 2 in country B. Of course, $\pi_{2}^{F}$ falls as $t$ increases, whereas $\pi_{123}^{F}$ increases. Again, there are two opposing effects on the profit country A receives - the efficiencyenhancing reduction in trade costs, and their monopoly-creating consequences. For $t$ sufficiently large, the volume exported from $\mathrm{A}$ to $\mathrm{B}$ is so small that the second effect dominates, and $\frac{1}{3} \pi_{123}^{F}+\pi_{2}^{F}$ increases with further increases in $t$.

A similar reasoning explains why $M^{I}$ increases relative to $M^{F}$ with increasing fixed costs. The higher the fixed cost is, the more attractive the merger to structure $M^{I}$ is, since country A's welfare is reduced by fixed costs equal to $\left(\frac{1}{2}+\frac{1}{2}\right) f$ in structure $M^{I}$, whereas it is reduced by $(1+z) f$ with $M^{F}$. For $f$ large enough, the higher fixed cost in $M^{F}$ will dominate the higher variable surplus it may entail.

Finally, $W^{F}$ is non-monotonic in $t$, since $W^{F}$ first falls and then increases in $t$. As a result, market structure $M^{F}$ tends to be most preferred for either low trade costs and high fixed costs, or for high trade costs and low fixed costs, but to be inferior to $M^{I}$ when both trade costs and fixed costs are high. Observe that $W^{F}$ is affected by $t$ only as it affects the profits made by firms 134 and 2 in country B. Of course, $\pi_{2}^{F}$ falls as $t$ increases, whereas $\pi_{123}^{F}$ increases. Again, there are two opposing effects on the profit country A receives - the efficiency-enhancing reduction in trade costs, and their monopoly-creating consequences. When $t$ is large enough, the volume exported from A to B is so small that the second effect dominates, and $\frac{1}{3} \pi_{123}^{F}+\pi_{2}^{F}$ increases with further increases in $t$.

The general picture that emerges is thus that when mergers are driven by relatively small fixed and trade cost savings, it is preferable from a national point of view that mergers are biased towards participation of foreign firms. However, for sufficiently high fixed and trade cost savings equal participation is preferred.

\subsection{Most preferred ownership structure in the Variable Cost Synergy Model}

Not surprisingly, welfare issues are substantially more involved in the VCS Model. Figs 4 and 5 illustrate the pattern of the most preferred structure in the $(t, c)$ plane. Recall that a high value of $c$ corresponds to pronounced synergies in a 
certain sense. As can be seen from Fig. 3,4 and 5, there are similarities between the pattern of most preferred market structures in the present model and in the previous model. In both cases, a merger between the two foreign owners is most preferred for low levels of synergies (as defined above), a merger involving both the foreign owner and a domestic owner is preferred for somewhat larger synergies, and a purely international duopoly is most preferred with even more pronounced synergies. What is novel here, however, is that mergers between the domestic owners can be preferred when synergies are strong. This may then take the form of either a purely domestic merger, or a merger also involving a foreign owner.

A comparison of the figures depicting equilibrium market structures with those illustrating the structures socially most preferred, reveals another similarity between the two oligopoly models: there is a discrepancy between private social incentives for merger for low levels of the synergies, whereas for sufficiently pronounced synergies these incentives tend to coincide.

(Figures 4 and 5 here)

\subsection{National champions}

As mentioned in the Introduction, the practice of promoting domestic mergers in order to create competitive firms - "national champions" - has been fairly widespread. From a theoretical point of view, it is easy to identify circumstances under which such mergers would increase welfare in an open economy, while being undesirable in a closed economy, when in both cases comparing with the initial situation. However, once the endogenous nature of mergers is taken into account, the more relevant question is whether a "national champion" merger is desirable, when equal synergies could be obtained through an international merger?

The models above have some immediate implications for this issue. A national champion in market $A$, say, would in the model correspond to a merger between owners 1 and 2, possibly including one of the two other owners; that is, structures $M^{T}$, or $M^{H}$. Such mergers are not desirable from the point of view of national welfare in the FCS Model. On the contrary, there is a tendency for 
mergers between foreign firms to be desirable. Hence, it seems as if exploitation of fixed costs savings is not a valid rationale for creating national champions. In the VCS Model, however, there seems to be more scope for such a policy, depending on the extent of these synergies. As was shown, the most preferred market structure for limited synergies was either $M^{U}$ or $M^{F}$ — structures involving mergers between foreign firms. But, for sufficiently pronounced synergies, the most preferred structure has a bias toward domestic mergers, i.e., structure $M^{H}$. This thus suggests that a policy of promoting the "national champion" may indeed be welfare maximizing if there are sufficiently pronounced variable cost synergies, also taking into account other structures in which synergies can be exploited.

\section{Concluding discussion}

Mergers between domestic firms are in policy making often viewed very differently from mergers between foreign firms. But theory has very little to say about whether or when this is warranted, and about the more fundamental questions of the driving forces behind mergers in international markets. The purpose of this paper has been to shed some light on these issues. To achieve this the paper has applied a theory of endogenous merger formation to an international oligopoly market.

In the model, high trade costs tend to induce firms to undertake FDI (i.e., to merge internationally) in order to "jump" these barriers, as is commonly claimed. But, they may also increase domestic firms' incentives to invest in the same assets into account, and that sufficiently high trade barriers instead induce domestic agents to purchase the assets (i.e., to merge domestically). This would not be an issue if the assets that a foreign firm wants to acquire were supplied infinitely elastically. But, when they are supplied inelastically the cost of investing in the market - the acquisition of the assets - may be affected by the behavior of domestic competitors, and in particular by their desire to purchase the same assets.

The analysis has also pointed to the possibility that the merger formation may 
yield a collectively efficient outcome for owners as a whole. As a result, private and social incentives for mergers tend to differ for low levels of cost savings and synergies, but to converge for more pronounced synergies in the linear models we have examined.

It has furthermore been shown how a market structure with purely domestic mergers is never the socially most preferred structure in this context. When mergers are driven by the desire to save on fixed costs, it is, from a social point of view best to have either purely international mergers, or, when fixed cost savings are not very large, to have mergers between foreign firms only. However, when mergers exploit marginal cost synergies, then mergers involving domestic firms may be desirable, if these synergies are sufficiently pronounced.

These results seem to imply that there is scope for welfare-enhancing merger policies. But, the endogenous nature of mergers in the present analysis, as well as the international dimension of the analysis, imply that the optimal design of merger policy is here substantially more involved than in the traditional case of exogenous mergers in traditional closed-economy situations. Space considerations makes it impossible for us to characterize the optimal national merger policies for the two countries. Instead we will make a couple of remarks concerning merger policy that might indicate areas worthy of future investigations.

A potentially important aspect of merger policy in an international context is that the design of the policy vis-a-vis international mergers may influence "the terms-of trade" of mergers. Let us leave the four-owner set-up for a moment and think in terms of the simplest case: a duopoly-to-monopoly merger between a domestic and a foreign firm. Whether or not this merger will increase domestic welfare depends partly on the division of the monopoly profit it yields. The firms may thus realize that the domestic competition authority will not accept the merger unless a sufficiently large fraction of the profit accrues to the domestic owner, and will find it worthwhile to form their agreement so that it is acceptable to the competition authority. Conducted in this manner, the merger policy thus takes on a strategic role similar to that of strategic trade policy.

There are also more indirect ways in which merger policy can affect the merger 
terms-of-trade. For instance, consider an industry in which there are three completely symmetric firms, two domestic and one foreign firm, in which there are private gains from merging in the traditional sense. Suppose the domestic competition authority makes a credible announcement that it will not accept a merger between the two domestic firms. This would imply that any merger must involve the foreign firm. If there are strong strategic synergies to be reaped from the merger, then this policy may be counter-productive from a social point of view: the foreign firm can play one domestic firm against the other, and get a large share of the profit in the merged entity, since the "outside opportunities" are small for the domestic firms. On the other hand, if there are mainly fixed cost synergies, so that the outside firm is the prime beneficiary from the merger, it is to the foreign firm's disadvantage that it has to be part of any merger. The domestic firms then have good "outside opportunities", in contrast to the foreign firm.

This latter example suggests that the design of optimal national merger policies may be complicated by the fact that these policies not only affect which proposed mergers that might or might not be accepted. The merger policies may also influence the welfare obtained in the various structures. A restrictive policy vis-a-vis one structure may affect the payoffs received by domestic owners in other structures.

Yet another complicating factor for the design of optimal policies, is the fact that there are numerous ways in which governments can affect trading costs (which here have been treated as exogenous). For instance, tariffs, import licenses, customs red tape and national product standards, all tend to increase the cost of importing, whereas government supplied infrastructure for transportation, import subsidies, etc., can contribute to lower trade costs. In order to determine countries' individual incentives with regard to trade policy, we would need to distinguish between trade costs to each of the two markets above, and this is beyond the scope of this paper. But, it seems plausible that trade costs may affect payoffs in international mergers not only by influencing the size of the profits to be divided among the participating owners, but also by affecting the distribution 
of payoffs within merged entities, through their impact on the parties' bargaining positions.

Let us end by mentioning several weaknesses of the analysis. Our approach combines a standard type of IO merger model, with a cooperative coalition formation model, and it inherits several of the weaknesses of both these strands of literature. First, one drawback of the cooperative approach is that we do not know how the solution might be implemented non-cooperatively in any reasonable fashion. We would prefer to have such a non-cooperative under-pinning, provided that it were also intuitively appealing. However, lacking such a model, we believe some insights can still be obtained from the use of a cooperative approach to merger formation. ${ }^{26}$

Secondly, while the model seeks to address one main weakness in the IO literature on mergers - the exogeneity of merger formation - it retains another potentially serious weakness when interpreted in the "IO fashion": it does not verify that the assumed pre-merger allocation of ownership is an equilibrium, given the possibility to merge. However, as mentioned above, there is an alternative interpretation of the model, which is not subject to this criticism. In this interpretation mergers do not take place because firms suddenly are allowed to merge, but in response to an exogenous event, such as the lowering of trade cost.

Finally, we assume that M\&A is the only feasible way of acquiring additional productive capacity in a market. As argued above, this restriction is relevant for many markets of considerable practical relevance. But, needless to say, the longer run aim must be to understand the general case where both greenfield entry and M\&A are permitted. It seems clear that in situations where productive resources necessary for greenfield entry are supplied locally, infinitely elastically, and at a sufficiently low price, the incentives for M\&A are likely to be very limited. On the other hand, when productive capacity are sufficiently costly, they should not

\footnotetext{
${ }^{26}$ There seems to be a much more eclectic view of cooperative (coalitional) game theory among game theorists than among non-specialists who apply game-theoretic concepts. For instance, Osborne and Rubinstein (1996, p. 256) writing about the differences between non-cooperative and coalitional models, states that "[w]e do not view either of the two approaches as superior or more basic. Each of them reflects different kinds of strategic considerations and contributes to our understanding of strategic reasoning."
} 
have any impact on merger patterns. In this case the analysis of our paper should be more relevant. But, whenever these resources are supplied at intermediate prices, and are not supplied infinitely elastically, the issue becomes substantially more involved. One would then have to take into consideration the incentives and possibilities, for instance, for incumbent local firms both to purchase such resources to deter entry, and to merge. Whether this will be possible will depend on a number of factors, such as the assumed timing of events, and the exact demand and cost conditions. Hopefully, one can see the above as a stepping stone in the direction of this more complete analysis.

\section{A. Appendix}

\section{A.1. Derivation of inequality (3.2)}

Let there be two firms, 1 and 2, where firm 2 is an exporter to the market under consideration. Profits of firms 1 and 2 are

$$
\begin{gathered}
\pi_{1}=P\left(q_{1}+q_{2}\right) q_{1}-c \cdot q_{1}-F_{1} \\
\pi_{2}=P\left(q_{1}+q_{2}\right) q_{2}-c \cdot q_{2}-t q_{2}-F_{2}
\end{gathered}
$$

The FOC

$$
\begin{gathered}
P\left(q_{1}+q_{2}\right)+q_{1} P^{\prime}\left(q_{1}+q_{2}\right)-c=0 \\
P\left(q_{1}+q_{2}\right)+q_{2} P^{\prime}\left(q_{1}+q_{2}\right)-c-t=0
\end{gathered}
$$

imply that

$$
P^{\prime}(Q)\left(q_{2}-q_{1}\right)=t
$$

and hence that $q_{1}>q_{2}$ for $t>0$. Totally differentiating the FOCs,

$$
\begin{aligned}
& \frac{d q_{1}}{d t}=-\frac{1}{D}\left(P^{\prime}+q_{1} P^{\prime \prime}\right) \\
& \frac{d q_{2}}{d t}=\frac{1}{D}\left(2 P^{\prime}+q_{1} P^{\prime \prime}\right)
\end{aligned}
$$

where

$$
D \equiv\left(P^{\prime}\right)^{2}+\left(P^{\prime}+q_{1} P^{\prime \prime}\right) P^{\prime}+\left(P^{\prime}+q_{2} P^{\prime \prime}\right) P^{\prime}
$$


The aggregate equilibrium profit net of the trade costs facing firm 2 is

$$
\bar{R}(t)=P\left(q_{1}(t)+q_{2}(t)\right)\left(q_{1}(t)+q_{2}(t)\right)-c q_{1}(t)-c q_{2}(t)
$$

Differentiating w.r.t. the trade cost, taking into account the FOCs, yields

$$
\frac{d \bar{R}(t)}{d t}=\frac{q_{2}\left(P^{\prime}\right)^{2}}{D}
$$

Necessary and sufficient for this to be positive is that $q_{2}>0$ and $D>0$. Sufficient for the latter is in turn that the outputs are strategic substitutes, as assumed, since this implies that $P^{\prime}+q_{1} P^{\prime \prime}<0$ and $P^{\prime}+q_{2} P^{\prime \prime}<0$. This establishes the sign of the RHS of (3.2).

\section{A.2. Proofs of statements concerning the TCS Model and the FCS Model}

The TCS Model is formally a special case of the FCS Model, where $f=0$. It is therefore most convenient to first derive the necessary equilibrium quantities, profits and welfare in the different structures, in the context of the FCS Model.

\section{A.2.1. Equilibrium quantities, profits and welfare}

(i) In structure $M^{O}$ the product market equilibrium is the same in both countries. ${ }^{27}$ With $t \leq 1 / 3$, and for $i=1, . ., 4$

$$
q_{i d}^{O}=\frac{1}{5}(1+2 t) \quad q_{i e}^{O}=\frac{1}{5}(1-3 t) \quad \pi_{i}^{O}=\frac{1}{25}(1+2 t)^{2}+\frac{1}{25}(1-3 t)^{2}-f
$$

With $1 / 3<t \leq 1 / 2$, and for $n=1, \ldots 4$ :

$$
q_{i d}^{O}=\frac{1}{3} \quad q_{i e}^{O}=0 \quad \pi_{i}^{O}=\frac{1}{9}-f
$$

Welfare in country $\mathrm{A}$ is

$$
W^{O}=C S^{O}+\pi_{1}^{O}+\pi_{2}^{O}
$$

or

$$
W^{O}=\left\{\begin{array}{l}
\frac{4}{7}\left(3-3 t+7 t^{2}\right)-2 f \text { for } t \leq 1 / 3 \\
\frac{4}{9}-2 f \text { for } 1 / 3 \leq t \leq 1 / 2
\end{array}\right.
$$

${ }^{27}$ Calculations have partly been done in Derive ver. 3.00, and the plots have been done in Scientific WorkPlace ver. 2.01, Build 91. 
(ii) Structures $M^{T}$ and $M^{U}$ are the same, but with reversed roles for firms 1 and 2 , on the one hand, and firms 3 and 4 , on the other. In structure $M^{T}$, for $t \leq 1 / 3$,

$$
\begin{aligned}
& q_{12 d}^{T}=\frac{1}{4}(1+2 t) \quad q_{12 e}^{T}=\frac{1}{4}(1-3 t) \quad q_{n d}^{T}=\frac{1}{4}(1+t) \quad q_{n e}^{T}=\frac{1}{4}(1-2 t) ; n=3,4 \\
& \pi_{12}^{T}=\frac{1}{16}(1+2 t)^{2}+\frac{1}{16}(1-3 t)^{2}-f \quad \pi_{n}^{T}=\frac{1}{16}(1+t)^{2}+\frac{1}{16}(1-2 t)^{2}-f ; n=3,4
\end{aligned}
$$

and for $1 / 3<t \leq 1 / 2$,

$$
\begin{aligned}
& q_{12 d}^{T}=\frac{1}{4}(1+2 t) \quad q_{n d}^{T}=\frac{1}{4}(1+t) \quad q_{n e}^{T}=\frac{1}{4}(1-2 t) ; n=3,4 \\
& \pi_{12}^{T}=\frac{1}{16}(1+2 t)^{2}-f \quad \pi_{n}^{T}=\frac{1}{9}+\frac{1}{16}(1-2 t)^{2}-f ; n=3,4
\end{aligned}
$$

Welfare in country A is in structure $M^{T}$

$$
W^{T}=\left\{\begin{array}{l}
\frac{1}{32}\left(13-16 t+30 t^{2}\right)-f \text { for } t \leq 1 / 3 \\
\frac{1}{32}\left(11-4 t+12 t^{2}\right)-f \text { for } 1 / 3 \leq t \leq 1 / 2
\end{array}\right.
$$

and in structure $M^{U}$

$$
W^{U}=\left\{\begin{array}{l}
\frac{1}{32}\left(17-14 t+21 t^{2}\right)-2 f \text { for } t \leq 1 / 3 \\
\frac{1}{72}\left(41-36 t+36 t^{2}\right)-2 f \text { for } 1 / 3 \leq t \leq 1 / 2
\end{array}\right.
$$

(iii) Structures $M^{V}, M^{X}, M^{Y}$ and $M^{Z}$ are the same, except that the identity of the two merging owners are different. In structure $M^{V}$, for $t \leq 1 / 3$,

$$
\begin{aligned}
& q_{13 A}^{V}=q_{13 B}^{V}=\frac{1}{4}(1+t) \quad q_{n d}^{V}=\frac{1}{4}(1+t) \quad q_{n e}^{V}=\frac{1}{4}(1-3 t) ; n=2,4 \\
& \pi_{13}^{V}=\frac{1}{8}(1+t)^{2}-f \quad \pi_{n}^{V}=\frac{1}{16}(1+t)^{2}+\frac{1}{16}(1-3 t)^{2}-f ; n=2,4
\end{aligned}
$$

and for $1 / 3<t \leq 1 / 2$,

$$
\begin{gathered}
q_{13 A}^{V}=q_{13 B}^{V}=q_{n d}^{V}=\frac{1}{3} \quad q_{n e}^{V}=0 ; n=2,4 \\
\pi_{13}^{V}=\frac{2}{9}-f \quad \pi_{n}^{V}=\frac{1}{9}-f ; n=2,4
\end{gathered}
$$

Welfare in country A is

$$
W^{j}=\left\{\begin{array}{l}
\frac{1}{32}\left(15-10 t+23 t^{2}\right)-\frac{3}{2} f \text { for } t \leq 1 / 3 \\
\frac{4}{9}-\frac{3}{2} f \text { for } 1 / 3 \leq t \leq 1 / 2
\end{array} ; j=V, X, Y, Z\right.
$$


(iv) In structure $M^{N}$, for $t \leq 1 / 2$,

$$
\begin{aligned}
& q_{i d}^{N}=\frac{1}{3}(1+t) \quad q_{i e}^{N}=\frac{1}{3}(1-2 t) ; i=12,34 \\
& \pi_{i}^{N}=\frac{1}{9}(1+t)^{2}+\frac{1}{9}(1-2 t)^{2}-f ; i=12,34
\end{aligned}
$$

Welfare in country A is

$$
W^{N}=\frac{1}{18}\left(8-8 t+11 t^{2}\right) \text { for } t \leq 1 / 2
$$

(v) Structures $M^{I}$ and $M^{I^{\prime}}$ are symmetric. In structure $M^{I}$,

$$
q_{i A}^{I}=q_{i B}^{I}=\frac{1}{3} \quad \pi_{i}^{I}=\frac{2}{9}-f ; i=13,24
$$

Welfare in country A is

$$
W^{I}=W^{I^{\prime}}=\frac{4}{9} \text { for } t \leq 1 / 2
$$

(vi) Structures $M^{H}$ and $M^{H^{\prime}}$ are symmetric with the roles of owners 3 and 4 reversed. In structure $M^{H}$, for $t \leq 1 / 2$,

$$
\begin{aligned}
& q_{123 d}^{H}=\frac{1}{3}(1+t) \quad q_{123 e}^{H}=q_{4 d}^{H}=\frac{1}{3} \quad q_{4 e}^{H}=\frac{1}{3}(1-2 t) \\
& \pi_{123}^{H}=\frac{1}{9}(1+t)^{2}+\frac{1}{9}-f \quad \pi_{4}^{H}=\frac{1}{9}+\frac{1}{9}(1-2 t)^{2}-f
\end{aligned}
$$

Welfare in country $\mathrm{A}$ is, for $t \leq 1 / 2$,

$$
W^{H}=W^{H^{\prime}}=\frac{1}{54}\left(20-4 t+7 t^{2}\right)-\frac{2}{3} f
$$

(vii) Structures $M^{F}$ and $M^{F^{\prime}}$ are symmetric with the roles of owners 1 and 2 reversed. In structure $M^{F}$, for $t \leq 1 / 2$,

$$
\begin{aligned}
& q_{134 d}^{F}=\frac{1}{3}(1+t) \quad q_{134 e}^{F}=q_{2 d}^{F}=\frac{1}{3} \quad q_{2 e}^{F}=\frac{1}{3}(1-2 t) \\
& \pi_{134}^{F}=\frac{1}{9}(1+t)^{2}+\frac{1}{9}-f \quad \pi_{2}^{F}=\frac{1}{9}+\frac{1}{9}(1-2 t)^{2}-f
\end{aligned}
$$

Welfare in country $\mathrm{A}$ is, for $t \leq 1 / 2$,

$$
W^{F}=W^{F^{\prime}}=\frac{1}{27}\left(14-10 t+13 t^{2}\right)-\frac{4}{3} f
$$




\section{A.2.2. Constraints ensuring non-negative profits}

For each market structure constraints on $t$ ensure that quantities are positive. But, there are limits to how large the fixed cost can be, in order to have nonnegative profits. These constraints typically depend both on $t$ and $f$. The profit functions are different in the two intervals $t \leq 1 / 3$ and $1 / 3<t \leq 1 / 2$, and one therefore has to look at each range separately. It can be shown that for $t \leq 1 / 3$, the most binding constraint is that which guarantees each $\pi_{i}^{O} \geq 0$,

$$
\frac{1}{25}\left(2-2 t+13 t^{2}\right) \geq f
$$

and that for $1 / 3<t \leq 1 / 2$ the most binding restriction is the one that ensures $\pi_{4}^{H}=\pi_{3}^{H^{\prime}}=\pi_{2}^{F}=\pi_{1}^{F^{\prime}} \geq 0$,

$$
\frac{2}{9}\left(1-2 t+2 t^{2}\right) \geq f
$$

In Fig. 2 these constraints are plotted as the curve

$$
R(t)=\left\{\begin{array}{lll}
\frac{1}{25}\left(2-2 t+13 t^{2}\right) & \text { if } & 0 \leq t \leq 1 / 3 \\
\frac{2}{9}\left(1-2 t+2 t^{2}\right) & \text { if } & 1 / 3<t \leq 1 / 2
\end{array}\right.
$$

\section{A.2.3. Proof of Proposition 1}

The asymmetry of the dom relation implies that it suffices to show that the market structures stated in Proposition 1 dominate all other structures in the specified region; it follows from the asymmetry of the dom relation that they are then also undominated by all structures. Consider first Part (i) of the Proposition.

(a) $M^{I}$ dom $M^{i} \in \mathcal{M}, i \neq I^{\prime}, V, X, Y, Z, O$ : In each case there is one decisive group comprising all owners. It is straightforward to verify that $\pi^{I}>\pi^{i}$ if $t<2 / 5$. Hence, $M^{I}$ dom $M^{i}$ if $t<2 / 5$.

(b) $M^{I}$ dom $M^{i}, i=V, X, Y, Z$ : There is one decisive group comprising two owners. For instance, let $i=V$, so that the decisive group consists of owners 2 and 4. $\pi_{24}^{I}>\pi_{2}^{V}+\pi_{4}^{V}$, with $t \leq 1 / 3$, iff

$$
\frac{1}{15}<t<\frac{1}{3}
$$


The same condition applies for $i=X, Y, Z$.

(c) $M^{I}$ dom $M^{O}$ : There are two completely symmetric decisive groups, $\mathcal{G}_{1}^{I O}=$ $\{1,3\}$ and $\mathcal{G}_{2}^{I O}=\{2,4\} . \pi_{13}^{I}>\pi_{1}^{O}+\pi_{3}^{O}$, with $t<1 / 3$, iff

$$
-7-18 t+117 t^{2}<0
$$

This condition always holds for $t<1 / 3$.

This completes the proof of Part (i) of the Proposition. Now turn to Part (ii). (a) $M^{N} \operatorname{dom} M^{i}, M^{i} \in \mathcal{M}, i \neq T, U$, O: In each case there is one decisive group comprising all owners. It is straightforward to verify that $\pi^{N}>\pi^{i}$ if $2 / 5<t \leq$ $1 / 2$, and hence $M^{N}$ dom $M^{i}$ for this range.

(b) $M^{N} \operatorname{dom} M^{i}, i=T, U$ : There is one decisive group comprising two owners. For instance, let $i=T$, so that the decisive group consists of owners 3 and 4 . In the region $2 / 5<t \leq 1 / 2, \pi_{34}^{N}>\pi_{3}^{T}+\pi_{4}^{T}$ iff

$$
9-20 t-4 t^{2}<0
$$

i.e., iff $t>(\sqrt{34}-5) / 2 \approx .415$. Hence, $M^{N}$ dom $M^{T}$ in this region. An identical reasoning applies to $M^{U}$.

(c) $M^{N}$ dom $M^{O}$ : There are two completely symmetric decisive groups, $\mathcal{G}_{1}^{I O}=$ $\{1,2\}$ and $\mathcal{G}_{2}^{I O}=\{3,4\} . \pi_{12}^{N}>\pi_{1}^{O}+\pi_{2}^{O}$ iff $t>2 / 5$. Hence, $M^{N}$ dom $M^{O}$ for $2 / 5<t \leq 1 / 2$.

This completes the proof of Part (ii), and thus the proof of Proposition 1.

\section{A.3. Proof of Proposition 2}

At $t=0$,

$$
\frac{d R(t)}{d t}=-\frac{2 P^{\prime}}{D}\left(P^{\prime}+q_{1} P^{\prime \prime}\right)<0
$$

which is negative since outputs are strategic substitutes. Thus there is a range of $t$, in the neighborhood of $t=0$, in which $R(t)<R(0)$, and thus where $\pi^{N}(t)<\pi^{I}$. This establishes Part (i). To see Part (ii), note that since

$$
R\left(t^{\prime \prime}\right)=\int_{0}^{t^{\prime \prime}} \frac{d \bar{R}(\tau)}{d t} d \tau+\text { const }
$$


where $R(0)=$ const, we have that

$$
R\left(t^{\prime \prime}\right)-R(0)=\int_{0}^{t^{\prime \prime}} \frac{d \bar{R}(\tau)}{d t} d \tau>0
$$

There must then be a range of values of $t<t^{\prime \prime}$ such that $R(t)>R(0)$, and thus where $\pi^{N}(t)>\pi^{I}$.

\section{References}

[1] Barros, P.P and L. Cabral, "Merger Policy in Open Economies," European Economic Review, May 1994, Vol. 38 No 5, 1041-1056.

[2] Dunning, J., "Trade, Location of Economic Activity and the MNE: A Search for and Eclectic Approach," in Ohlin, B. Hesselborn, P.-O. and P.M. Wijkman (eds) The International Allocation of Economic Activity. London: McMillan, 1977, 395-418.

[3] Economic Report of the President, US Government Printing Office, Washington, 1995.

[4] Espinosa, M. and E. Inarra, "von Neumann and Morgenstern Stable Sets in a Merger Game," International Journal of Game Theory, 1996.

[5] The European Union, "Efficiency and Competition Effects", European Economy 4, 1996.

[6] Head, K. and J. Ries, "International Mergers and Welfare under Decentralized Competition Policy," (mimeo), 1995.

[7] Horn, H. and J. Levinsohn, "Merger Policies and the GATT," mimeo, 1997.

[8] Horn, H. and L. Persson, "Endogenous Mergers in Concentrated Markets," Discussion Paper 1544, Centre for Economic Policy Research, 1997.

[9] Jenny, F., "French Competition Policy in Perspective," in Competition Policy in Europe and North America: Economic Issues and Institutions, W.S. Comanor et al. (eds), (New York: Harwood Academic), 1990. 
[10] JETRO, “JETRO White Paper on Foreign Direct Investment 1996," Japan External Trade Organization, available at http://www.jetro.go.jp.

[11] Greenberg, Joseph, "Coalition Structures," in Aumann, R. J. and Hart, S., ed., Handbook of Game Theory, Volume 2, Elsevier Science B.V., 1994.

[12] Horstmann, I. and J. Markusen, "Endogenous Market Structures in International Trade (Natura Facit Saltum)," Journal of International Economics 32, 1992, 109-129.

[13] Markusen, J. R., "Multinationals, Multi-plant Economies, and the Gains from Trade," Journal of International Economics 16, 1984, 205-206.

[14] Markusen, J. R., "The Boundaries of Multinational Enterprises and the Theory of International Trade," Journal of Economic Perspective, 1995, Vol. 9, No. 2, 169-189.

[15] Markusen, J. R. and A. Venables, "The Theory of Endowment, IntraIndustry Trade, and Multinational Trade," National Bureau of Economic Research Working Paper No. 5529, 1996.

[16] Ordover, J. and R. Willig, "Perspectives on Mergers and World Competition," in R. Grieson (ed.) Antitrust and Regulation (Lexington, Mass.: Heath, Lexington Books, 210-18, 1986.

[17] OECD, International Mergers and Competition Policy, Organisation for Economic Co-operation and Development, Paris, 1988.

[18] OECD, "Evolution of Priorities for the Program of Work 1995-1996," Trade Directorate, Organisation for Economic Co-operation and Development, Paris, 1995.

[19] Osborne, M. and A. Rubinstein, A Course in Game Theory," The MIT Press, 1996.

[20] Perry, M. and R. Porter, "Oligopoly and the Incentive for Horizontal Merger," American Economic Review, 1985, Vol. 75, 219-27. 
[21] Porter, M., The Competitive Advantage of Nations, (New York: The Free Press).

[22] Richardson, M., "Trade and Competition Policies: Concordia Discors?," University of Otago, mimeo, 1996.

[23] Rysman, M., "Competition Policy in Strategic Trade," University of Wisconsin, Madison, mimeo, 1997.

[24] Salant, S., Switzer, S. and R. Reynolds, "Losses Due to Merger: The Effects of an Exogenous Change in Industry Structure on Cournot-Nash Equilibrium," Quarterly Journal of Economics, 1983, 98, 185-99.

[25] Scherer, F.M., Competition Policies for an Integrated World Economy, The Brookings Institution, Washington, 1994.

[26] Shubik, Martin, Game Theory and the Social Sciences. Cambridge, Massachusetts: The MIT Press, 1983.

[27] Thrall, R. and W. Lucas, "n-person Games in Partition Function Form," Naval Research Logistics Quarterly, 1963, 10, 281-298.

[28] UNCTAD, World Investment Report, United Nations Conference on Trade and Development, 1996, 1998. 